\title{
Puerarin alleviates the progression of non-small cell lung cancer by regulating the miR-342/CCND1 axis
}

\author{
S. R. HUANG ${ }^{1, *}$, S. S. JIN ${ }^{2, *}$, B. XU ${ }^{3}$, R. P. WANG ${ }^{4, *}$ \\ ${ }^{1}$ Department of Emergency, Nanjing Hospital of Chinese Medicine affiliated to Nanjing University of Chinese Medicine, Nanjing University \\ of Chinese Medicine, Nanjing 210012, Jiangsu, China; ${ }^{2}$ Department of Oncology, The First Affiliated Hospital of Nanjing Medical University, \\ Nanjing, Jiangsu, 210029, China; ${ }^{3}$ Department of Respiratory Medicine, Nanjing Chest Hospital, Nanjing, Jiangsu 210029, China; ${ }^{4}$ Department \\ of Oncology, Jiangsu Province Hospital of Chinese Medicine, Nanjing, Jiangsu 210029, China
}

*Correspondence: gwobog@163.com

${ }^{\#}$ Contributed equally to this work.

Received November 7, 2019 / Accepted February 24, 2020

\begin{abstract}
Puerarin has recently been demonstrated to play anti-cancer roles in a series of human cancers, including non-small cell lung cancer (NSCLC), possibly through regulation of cancer-related microRNAs (miRNAs). The purpose of the present study was to further investigate the detailed role and underlying mechanism of puerarin on NSCLC progression. Cell viability and apoptosis were assessed using the Cell Counting kit-8 (CCK-8) assay and flow cytometry, respectively. Transwell assays were performed to determine cell migration and invasion abilities. The qRT-PCR assay was employed to detect the expression of miR-342 and cyclin D1 (CCND1) mRNA, and CCND1 protein expression was evaluated by western blotting. The targeted interaction between miR-342 and CCND1 was verified by dual-luciferase reporter assay and RNA immunoprecipitation (RIP) assay. We found that our data demonstrated that puerarin repressed cell viability, migration, invasion, and cell cycle progression, and enhanced the apoptosis of NSCLC cells. miR-342 overexpression hindered the migration, invasion and cell cycle progression, and accelerated the apoptosis of NSCLC cells. miR-342 inhibited CCND1 expression by directly binding to the 3'-UTR of CCND1. Moreover, miR-342 overexpression-mediated anti-migration, anti-invasion, anti-cell cycle progression, and pro-apoptotic effects were abated by co-transfection of pcDNA-CCND1. More importantly, puerarin inhibited CCND1 expression by upregulating miR-342. Additionally, puerarin hampered NSCLC cell progression in vitro and tumor growth in vivo by upregulating miR-342. In conclusion, our study suggested that puerarin hampered NSCLC progression in vitro and in vivo at least partly through regulating miR-342/CCND1 axis, highlighting a novel mechanism of puerarin exerting anti-cancer property in NSCLC.
\end{abstract}

Key words: non-small cell lung cancer (NSCLC), puerarin, miR-342, cyclin D1 (CCND1)

Lung cancer remains the leading cause of cancer incidence and mortality, with an estimated 2.1 million new lung cancer cases and 1.8 million deaths in 2018 worldwide [1]. Non-small cell lung cancer (NSCLC), mainly including lung adenocarcinoma and lung squamous cell carcinoma, accounts for approximately $85 \%$ of all lung cancer cases [2]. Although the developments of conventional therapeutic options and strategies have improved the prognosis, the 5 -year overall survival rate is still unsatisfactory $[3,4]$. Therefore, identifying novel promising therapeutic targets is required to make a breakthrough in outcomes for NSCLC patients.

Puerarin, the major bioactive ingredient derived from the root of the Pueraria lobata (Willd.) Ohwi, has been widely used as a food additive and alternative medicine $[5,6]$. The beneficial functions of puerarin are through to attribute to its vasodilatory activity [7], cardio-protective activity [8], antidiabetic activity [9], anti-inflammatory activity [10], and so on. Puerarin has recently been gaining increasing interest due to its anti-cancer properties in a wide variety of human cancers, including NSCLC $[11,12]$. The purpose of the study was to further investigate the detailed role and underlying mechanism of puerarin in NSCLC progression in vitro.

MicroRNAs (miRNAs), a large class of single-stranded, small non-coding RNAs with $\sim 22$ nucleotides in length, regulate complementary mRNAs by inducing translational repression and mRNA degradation, thereby playing crucial roles in cellular physiopathology processes. The mature miRNAs are present in the cytoplasm in the form of miRNA ribonucleoprotein complexes, called the RNA-induced silencing complexes (RISCs), where they direct the complex to target mRNAs $[13,14]$. Increasing evidence has illuminated the importance of miRNAs in cancer biology, including 
NSCLC $[15,16]$. miR-342 (also called miR-342-3p) has been reported to repress NSCLC progression in vitro through targeting RAP2B or anterior gradient 2 (AGR2) $[17,18]$.

Previous documents had demonstrated that puerarin hindered cancer progression by regulating the expression of cancer-related miRNAs $[19,20]$. However, the effect of the interplay between puerarin and miR-342 in NSCLC remains unknown. In this study, our results supported that puerarin or miR-342 overexpression repressed NSCLC cell migration, invasion, and enhanced cell apoptosis. Furthermore, our study suggested that puerarin played an anticancer role in NSCLC by regulating the miR-342/cyclin D 1 (CCND1) axis.

\section{Materials and methods}

Clinical samples and ethics statement. 35 pairs of NSCLC and adjacent noncancerous tissues were obtained from NSCLC patients at Nanjing Hospital of Chinese Medicine affiliated to the Nanjing University of Chinese Medicine. All tissues samples were stored in liquid nitrogen until use. Written informed consent was signed by all patients, and the protocol of this work was approved by the Ethics Committee of the Nanjing University of Chinese Medicine.

Cell culture and treatment. Human normal bronchial epithelial cell line 16HBE and two NSCLC cell lines (A549 ATCC ${ }^{\circ}$ CCL-185 and H1299 ATCC $^{\circ}$ CRL-5803) purchased from the American Type Culture Collection (ATCC, Manassas, VA, USA) were cultured in RPMI-1640 medium (\#C4111.0500, Genaxxon Bioscience, Ulm, Germany) supplemented with $10 \%$ heat-inactivated fetal bovine serum (\#abx131025, Cocalico Biologicals, Reamstown, PA, USA), $1 \%$ antibiotics (\#15070063, $100 \mathrm{U} / \mathrm{ml}$ penicillin and $100 \mu \mathrm{g} /$ $\mathrm{ml}$ streptomycin, Invitrogen, Carlsbad, CA, USA) in a humid atmosphere containing $5 \% \mathrm{CO}_{2}$ at $37^{\circ} \mathrm{C}$. For a preliminary observation for the role of puerarin in NSCLC progression in vitro, cells were treated with different concentrations $(0,5$, 10 , and $20 \mu \mathrm{M}$ ) of puerarin (ab142939, Abcam, Cambridge, UK) for $48 \mathrm{~h}$ or $10 \mu \mathrm{M}$ of puerarin for $48 \mathrm{~h}$.

Cell transfection. CCND1 overexpression plasmid (pcDNA-CCND1), the modified miR-342 mimic, miR-342 inhibitor (anti-miR-342), and corresponding negative control (pcDNA-NC, miR-NC mimic or anti-miR-342) were designed and synthesized by Ribobio (Guangzhou, Guangdong, China). Cells growing in 24-well plates were transfected with the indicated oligonucleotide $(50 \mathrm{nM})$ or/and plasmid (10 ng/ml) using Lipofectamine RNAiMAX transfection reagent (\#13778030, Invitrogen) according to the protocols of manufacturers.

Cell viability assay. Cell viability was determined using a Cell Counting kit-8 (CCK-8, CK04, Dojindo Laboratories, Kumamoto, Japan) in accordance with the manufacturer's protocols. Briefly, cells were seeded in a 96-well plate and treated with puerarin for $48 \mathrm{~h}$. After that, $10 \mu \mathrm{l}$ of CCK- 8 solution was added into each well and incubated at $37^{\circ} \mathrm{C}$ for
$2 \mathrm{~h}$. Absorbance at $450 \mathrm{~nm}$ was detected using a ChroMate 4300 microplate reader (Awareness Technologies Inc., Palm City, FL, USA) following the manufacturer's guidance.

Transwell assay of cell migration and invasion. Cell migration and invasion abilities were evaluated using a 24 well-Transwell chamber with $8-\mu \mathrm{m}$ pore filters (BD Biosciences, San Jose, CA, USA). To be brief, for migration assay, treated or transfected cells $\left(5.0 \times 10^{4}\right)$ resuspended in serumfree medium were plated in the upper chamber with a non-coated membrane. For invasion assay, $5.0 \times 10^{4}$ cells were seeded in the upper chamber with a Matrigel-coated membrane (BD Biosciences). In both assays, RPMI-1640 medium containing 10\% FBS was added in the lower chamber. $24 \mathrm{~h}$ later, the cells penetrated through the pores of inserts were fixed with $4 \%$ paraformaldehyde and stained with $0.2 \%$ crystal violet. The number of migrated or invaded cells was determined and images were photographed under a light microscope (Nikon, Shinagawa, Tokyo, Japan).

Flow cytometry. Cell apoptosis and cell cycle were determined by flow cytometry using the Annexin V-FITC/PI Apoptosis detection kit (\#V13242, Invitrogen) and FxCycle ${ }^{\mathrm{Tm}}$ Violet Ready Flow ${ }^{\text {min }}$ reagent kit (\#F10347, Invitrogen), respectively, following the instructions of manufacturers. Data analyses were performed using an FC500 flow cytometer (Beckman Coulter, Krefeld, Germany) with CXP Cytometer 2.2 software.

Quantitative real-time PCR (qRT-PCR). Total RNA was extracted from treated or transfected cells using the RNeasy plus mini kit (\#74134, Qiagen, Hilden, Germany) following the manufacturer's protocols. The quality and quantity of RNA extracts were measured by a spectrophotometer (VITC Easy Shade, VITA Zahnfabrik, Bad Sackingen, Germany). cDNA was synthesized from RNA extracts using reverse transcriptase (\#18090010, Invitrogen), and then subjected to qRT-PCR for CCND1 mRNA quantification using SYBR Green I Master mix (\#04707516001, Roche Applied Science, Mannheim, Germany) with GAPDH as an internal control. The level of miR-342 was determined using the TaqMan reverse transcription kit (\#4366597, Applied Biosystems, Foster City, CA, USA) and TaqMan MicroRNA assay kit (\#4427975, Applied Biosystems) on the 7900HT Real-time PCR system (\#4329003, Applied Biosystems), and normalized to U6. Relative gene expression was quantified using the $2^{-\Delta \Delta \mathrm{Ct}}$ method.

Western blotting. Total protein was prepared using ice-cold RIPA lysis buffer (50 mM Tris-HCl, pH 7.5, $150 \mathrm{mM}$ $\mathrm{NaCl}, 1 \%$ Triton X-100, $0.1 \%$ SDS, $0.5 \%$ sodium deoxycholate) supplemented with $1 \times$ protease inhibitor cocktail (\#87786, Sigma-Aldrich, St. Louis, MO, USA). Proteins $(50 \mu \mathrm{g})$ were resolved on a $10 \%$ SDS denatured polyacrylamide gel, transferred onto a polyvinylidene fluoride (PVDF) membrane (Hybond P, Amersham Bioscience, Piscataway, NJ, USA), and then exposed to the appropriate antibodies: anti-Bcl-2 (\#4223, 1:1000; Cell Signaling Technology, Danvers, MA, USA), anti-Bax (\#5023, 1:1000; Cell Signaling Technology), 
anti-CCND1 (\#2978, 1:1000; Cell Signaling Technology), anti-MMP9 (\#13667, 1:1000; Cell Signaling Technology), anti-MMP2 (\#40994, 1:1000; Cell Signaling Technology), and anti- $\beta$-actin (\#4970, 1:1000; Cell Signaling Technology). The membranes were incubated with a horseradish peroxidaseconjugated IgG secondary antibody (\#79408, 1:2000; Cell Signaling Technology). Protein bands were detected using enhanced chemiluminescence (Amersham Bioscience) and the band intensities were quantified using the LabWorksTM Image Acquisition and Analysis Software (UVP Bioimaging System, UVP Inc., Upland, CA, USA).

Bioinformatics. Analysis of the molecular targets of miR-342 was carried out using microT-CDS software at http://diana.imis.athena-innovation.gr/DianaTools/index. php?r=microT_CDS/index.

Dual-luciferase reporter assay. CCND1 3'-untranslated region (3'-UTR) wild-type luciferase reporter plasmids containing the complementary sequence for miR-342 (CCND1-WT1 and CCND1-WT2) and site-directed mutant of target sequence (CCND1-MUT1 and CCND1MUT2) were obtained from Ribobio. 293T cells growing in 24-well plates were cotransfected with the indicated luciferase reporter $(10 \mathrm{ng} / \mathrm{ml})$ and $50 \mathrm{nM}$ of miR-NC mimic or miR-342 mimic. After $48 \mathrm{~h}$ post-transfection, the luciferase activity was measured using the LightSwitch Luciferase Assay reagent (SwitchGear Genomics, Carlsbad, CA, USA) following the instructions of manufacturers.
RNA immunoprecipitation (RIP) assay. RIP assay was carried out using a Magna RIP RNA Immunoprecipitation kit (Millipore, Billerica, MA, USA) following the manufacturer's instruction. In brief, cells were transfected with miR-NC mimic or miR-342 mimic for $48 \mathrm{~h}$. Then, cell lysates were prepared with ice-cold RIPA buffer and then incubated with anti-Argonaute2 (anti-Ago2, ab32381, Abcam) or IgG (ab150077, Abcam) antibody for $4 \mathrm{~h}$ at $4{ }^{\circ} \mathrm{C}$ before adding protein $\mathrm{A} / \mathrm{G}$ agarose for $4 \mathrm{~h}$. Beads were harvested by centrifugation and washed three times with ice-cold PBS. Lastly, total RNA was extracted from the beads using the RNeasy plus mini kit and the enrichment of CCND1 mRNA was determined by qRT-PCR.

Animal studies. All animal tests were done in accordance with the National Standard of the Care and Use of Laboratory Animals, and our study was approved by the Ethics Committee of the Nanjing University of Chinese Medicine. Six-week-old BALC/c nude mice $(n=24)$ were purchased from Hubei Research Center of Laboratory Animal (Wuhan, China) and were randomly divided into 4 groups ( $\mathrm{n}=6$ each group): control, puerarin $(100 \mathrm{mg} / \mathrm{kg} /$ day $)$, puerarin $(100 \mathrm{mg} / \mathrm{kg} /$ day $)+$ anti-miR-NC and puerarin $(100 \mathrm{mg} / \mathrm{kg} /$ day $)+$ anti-miR-342. A549 cells $\left(1 \times 10^{7}\right)$ were subcutaneously injected into the nude mice. When the tumor grew to a mean volume of $100 \mathrm{~mm}^{3}$, simultaneous administration with puerarin $(100 \mathrm{mg} / \mathrm{kg} /$ day $)$ by oral gavage and intratumoral injection of anti-miR-342 or anti-miR-NC were
A<smiles>O=c1c(-c2ccc(O)c(O)c2)coc2c(C3OC(CO)[C@@H](O)[C@H](O)[C@H]3O)c(O)ccc12</smiles>

C

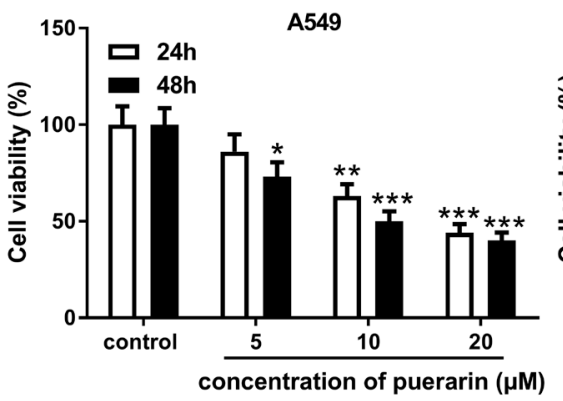

B
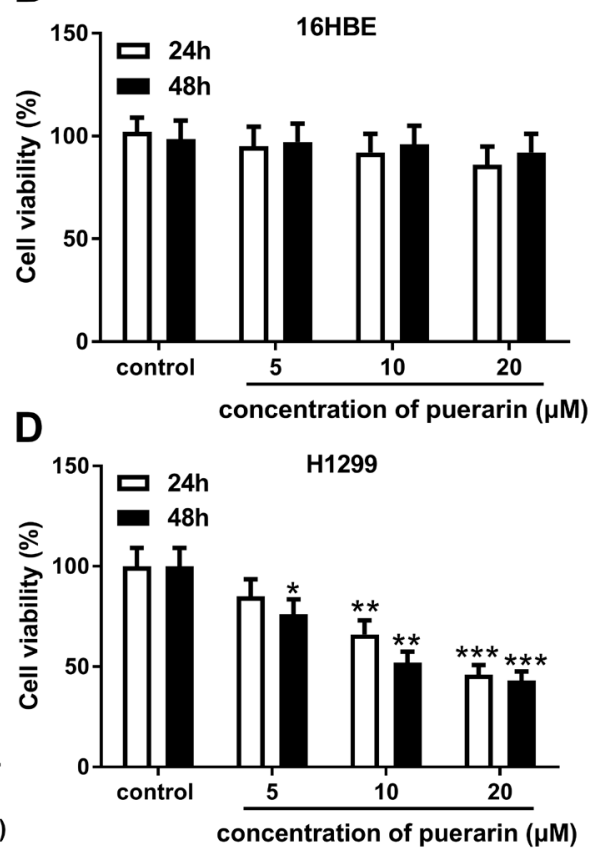

Figure 1. Puerarin repressed NSCLC cell viability. (A) The chemical structure of puerarin. Human normal bronchial epithelial cell line 16HBE (B), A549 (C), and H1299 (D) cells were treated with different concentrations $(0,5,10$, and $20 \mu \mathrm{M})$ of puerarin, followed by the detection of cell viability by CCK-8 assay. ${ }^{*} \mathrm{p}<0.05,{ }^{* *} \mathrm{p}<0.01$ or ${ }^{* * *} \mathrm{p}<0.001$ 

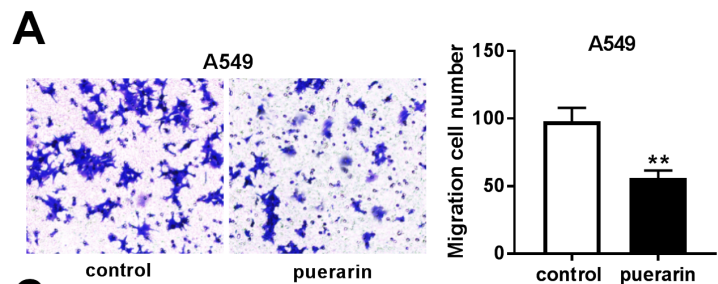

C
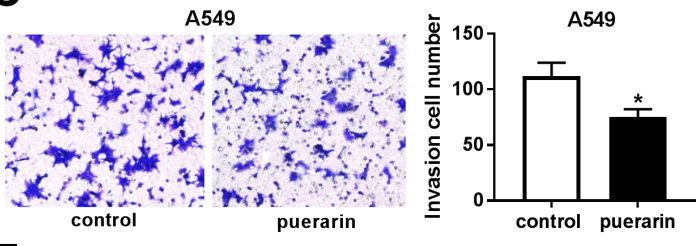

E

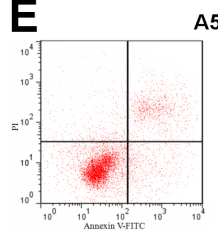

control

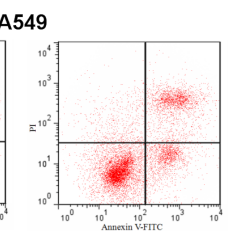

puerarin

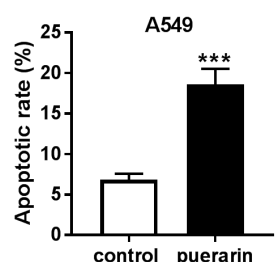

G
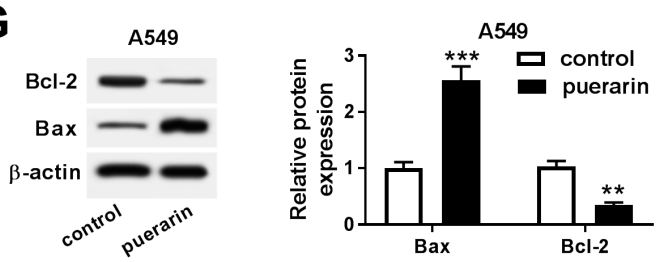

I

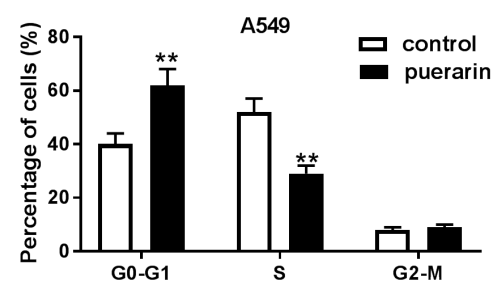

B
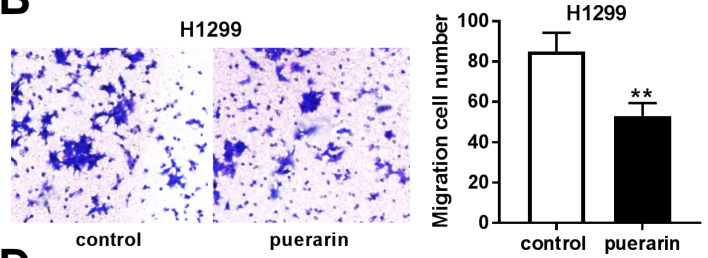

D
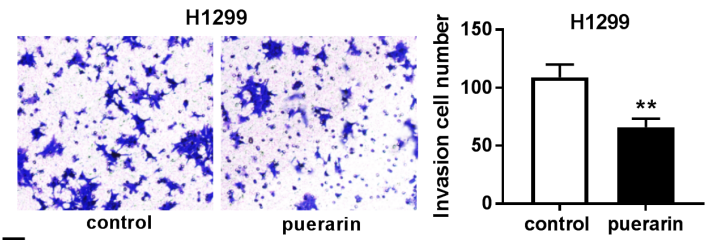

F

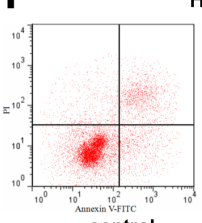

H1299
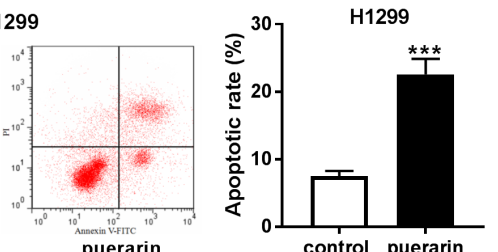

H
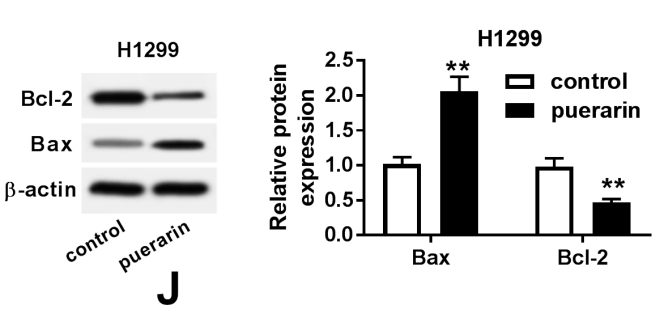

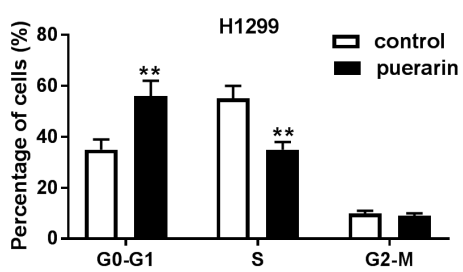

Figure 2. The effect of puerarin on NSCLC cell migration, invasion, and apoptosis. A549 and 1299 cells were treated with $10 \mu \mathrm{M}$ of puerarin, followed by the measurement of cell migration $(\mathrm{A}$ and $\mathrm{B})$ and invasion $(\mathrm{C}$ and $\mathrm{D})$ abilities by transwell assay, cell apoptosis by flow cytometry (E and $\mathrm{F})$, the expression levels of Bax and Bcl-2 by western blotting ( $\mathrm{G}$ and $\mathrm{H})$, cell cycle progression by flow cytometry $(\mathrm{I}$ and $\mathrm{J}) .{ }^{*} \mathrm{p}<0.05$, ${ }^{\star *} \mathrm{p}<0.01$ or ${ }^{\star * *} \mathrm{p}<0.001$

carried out. One week later, tumor volume was measured every other week. At the end of the experiments, all mice were euthanized and tumors were excised.

Statistical analysis. All data were presented as mean \pm standard deviation (SD) at least three independent experiments. Student's t-test and one-way ANOVA were used for the statistical analysis of all experiments. Differences were considered statistically significant at $\mathrm{p}<0.05$.

\section{Results}

Puerarin repressed NSCLC cell viability. For a preliminary observation for the role of puerarin in NSCLC, NSCLC cells were treated with different concentrations $(0,5,10$, and $20 \mu \mathrm{M}$ ) of puerarin (chemical structure, Figure 1A) for $48 \mathrm{~h}$.
As shown by the CCK- 8 assay, the viability of $16 \mathrm{HBE}$ cells was not affected by puerarin treatment (Figure 1B). Whereas, puerarin treatment triggered significant repression of cell viability in a dose-dependent manner in both A549 and H1299 cells (Figures 1C, 1D). These data together indicated the anti-cancer activity of puerarin in NSCLC cells.

Puerarin repressed the migration, invasion, and cell cycle progression and promoted the apoptosis of NSCLC cells. Then, we further investigated the effect of puerarin on NSCLC cell progression. A549 and H1299 cells were treated with $10 \mu \mathrm{M}$ of puerarin for $48 \mathrm{~h}$, followed by the determination of cell migration, invasion, apoptosis, and cell cycle progression. Transwell assays revealed that compared with negative control, puerarin treatment resulted in the inhibition of cell migration (Figures 2A, 2B) and invasion (Figures 2C, 
2D) abilities in both A549 and H1299 cells. Conversely, cell apoptosis was significantly promoted by puerarin induction (Figures 2E, 2F). Moreover, in contrast to the negative control, puerarin treatment triggered an obvious increase of Bax expression and a distinct decrease of $\mathrm{Bcl}-2$ expression in the two cells (Figures 2G,2H). Additionally, puerarin treatment significantly reduced the number of S-phase cells, indicating that puerarin repressed cell cycle progression in the two cells (Figures 2I, 2J). All these results suggested that puerarin repressed NSCLC cell migration, invasion, and cell cycle progression, and promoted cell apoptosis.

Overexpression of miR-342 hindered the migration, invasion, and cell cycle progression, and enhanced the apoptosis of NSCLC cells. Previous researches had reported miR-342 functioned as a tumor suppressor in NSCLC progression $[17,18]$. As a result, miR-342 expression was downregulated in NSCLC tissues and cells compared with normal controls (Supplementary Figure S1A and Figure 3A). We further explored the effect of miR-342 on NSCLC cell progression by transfection of miR-342 mimic. Transient introduction of miR-342 mimic, but not a scrambled control sequence, significantly elevated miR-342 expression in both A549 and H1299 cells (Figure 3B). Subsequent experiment results revealed that miR-342 overexpression led to a suppression of cell migration (Figures 3C, 3D) and invasion (Figures 3E, 3F) abilities, enhancement of cell apoptosis (Figures 3G, 3H), and a change of Bax and Bcl-2 levels (Figures 3I, 3J), as well as inhibition of cell cycle progression (Figures 3K, 3L). Together, these data hinted that miR-342 overexpression suppressed NSCLC cell migration, invasion, and cell cycle progression, and enhanced cell apoptosis.

CCND1 was a direct target of miR-342. miRNAs exert biological functions by a modulation of their target genes. In order to further explore the molecular mechanism by
A

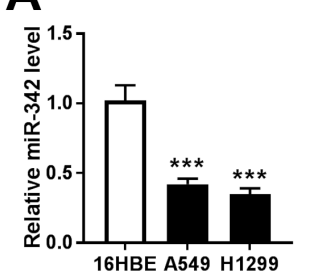

B

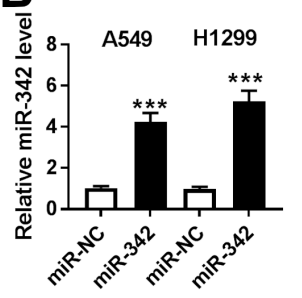

G
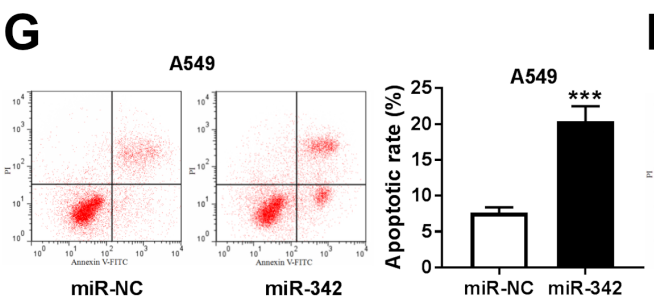

$\mathrm{H}$

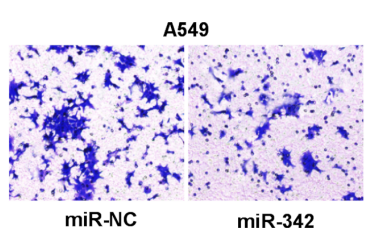

E
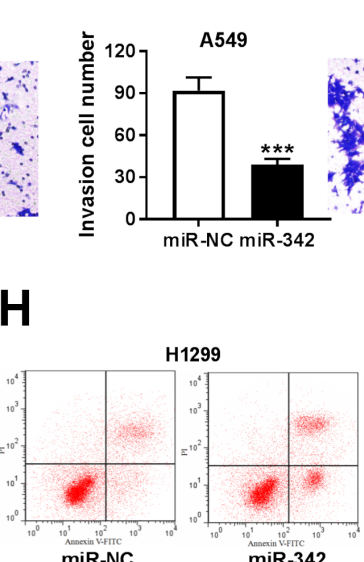

F
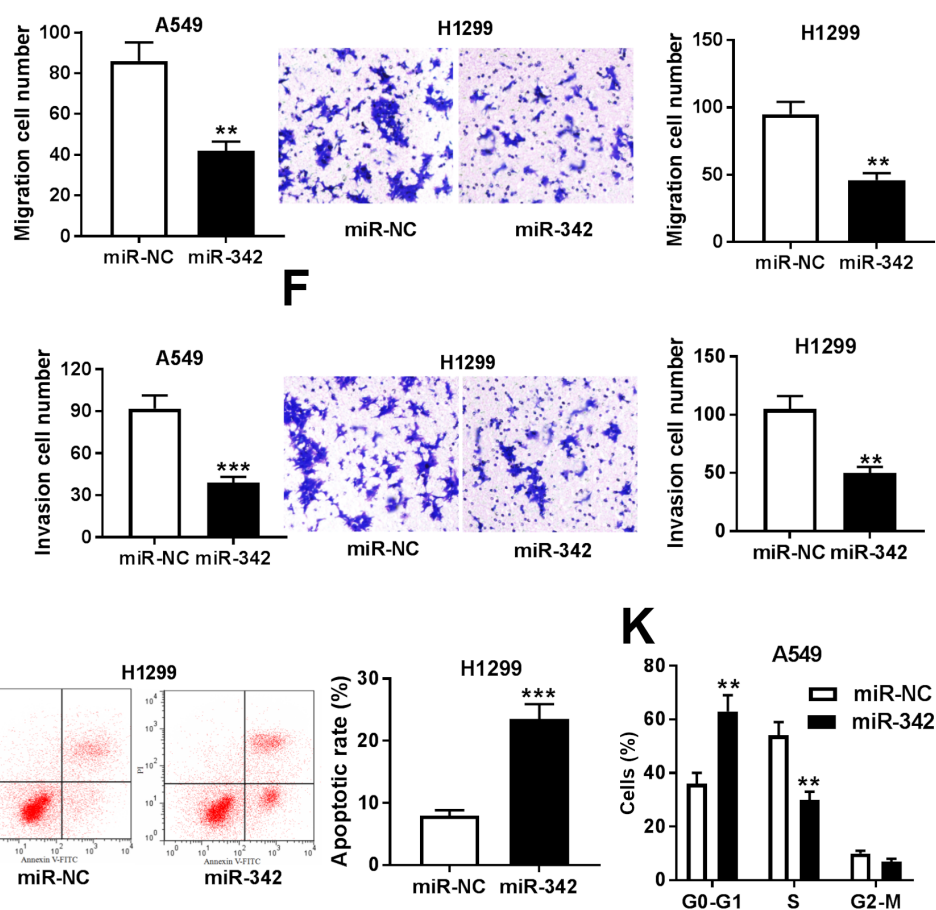

I

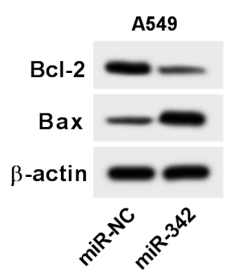

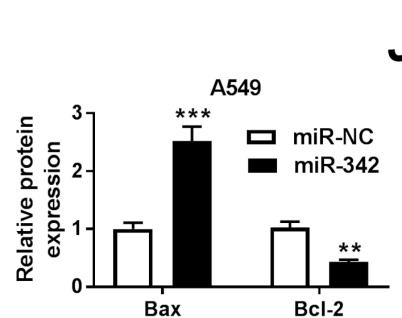

\section{J}
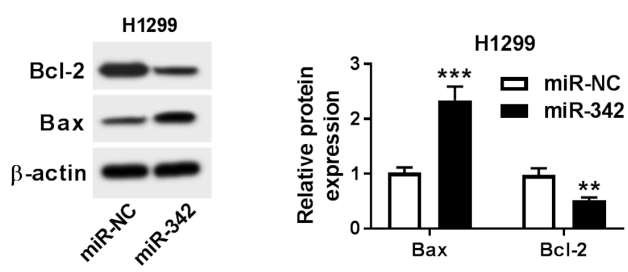

L

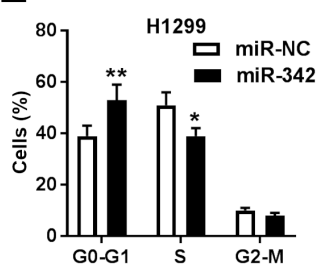

Figure 3. The effect of miR-342 overexpression on NSCLC cell migration, invasion, and apoptosis. (A) The expression of miR-342 by qRT-PCR in 16HBE, A549, and H1299 cells. A549 and H1299 cells were transfected with miR-NC mimic or miR-342 mimic, followed by the detection of miR-342 expression by qRT-PCR (B), cell migration (C and D), and invasion ( $\mathrm{E}$ and F) abilities by transwell assay, cell apoptosis by flow cytometry (G and H), the expression levels of Bax and Bcl-2 by western blotting (I and J), cell cycle progression by flow cytometry $(\mathrm{K}$ and $\mathrm{L})$. ${ }^{\star *} \mathrm{p}<0.01$ or ${ }^{\star * *} \mathrm{p}<0.001$ 
A

Position 1 :chr11:69467620-69467642

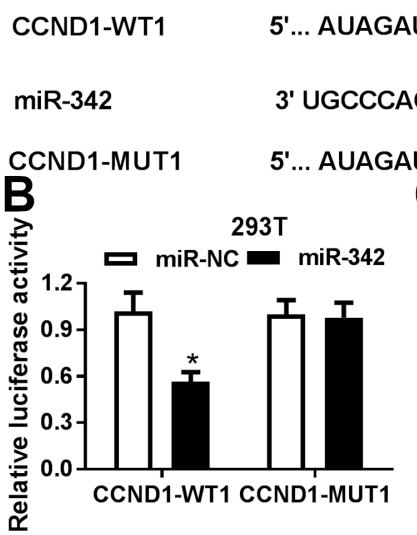

$\mathbf{F}$

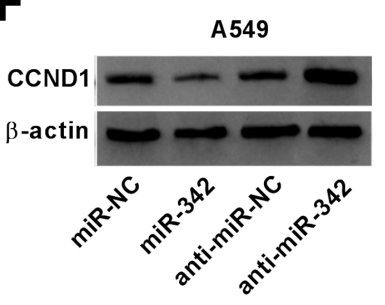

CCUUUUAUAgGUGAGA...3'<smiles>[c]1ccc[nH]1</smiles>

CACUCU $5^{2}$

UCCUUUUAUAgugagaC...3'

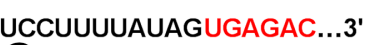

CCND1-MUT2
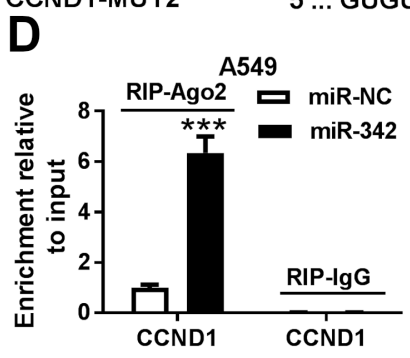

G
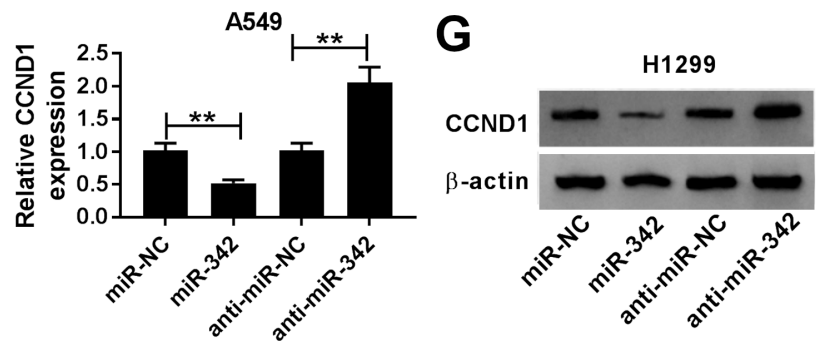

Position 2: chr11:69467895-69467916

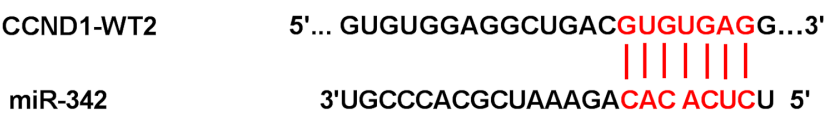

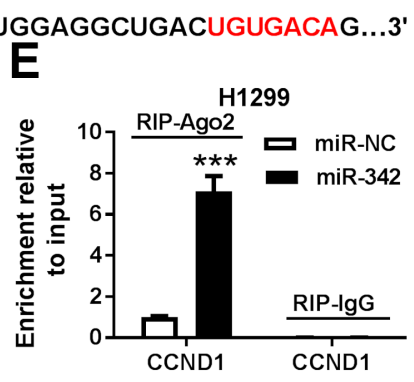

H1299

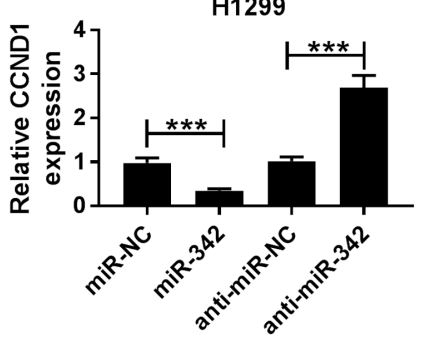

Figure 4. CCND1 was a direct target of miR-342. A) Nucleotide resolution of the predicted miR-342 binding sites in the 3'-UTR of CCND1 mRNA and the mutation of seeded sequence. B, C) The relative luciferase activity in 293T cells transfected with CCND1 3'-UTR wild-type luciferase reporter (CCND1-WT1 or CCND1-WT2) or site-directed mutation of seeded sequence (CCND1-MUT1 or CCND1-MUT2), together with miR-342 mimic or miR-NC mimic. D, E) The enrichment of CCND1 mRNA by qRT-PCR in RISC of A549 and H1299 cells transfected with miR-342 mimic or miR-NC mimic using anti-Ago2 or IgG antibody. F, G) CCND1 expression by western blotting in A549 and H1299 cells transfected with miR-342 mimic, antimiR-342 and, corresponding negative control. ${ }^{\star} \mathrm{p}<0.05,{ }^{* *} \mathrm{p}<0.01$ or ${ }^{* * *} \mathrm{p}<0.001$

miR-342 regulated NSCLC cell progression, we carried out a detailed analysis of the molecular targets of miR-342. Using microT-CDS software, the predicted data showed two putative miR-342 binding sites in the 3'-UTR of CCND1 mRNA (Figure 4A). When we performed dual-luciferase reporter assays, cotransfection of the luciferase reporter and miR-342 mimic into $293 \mathrm{~T}$ cells produced a lower luciferase activity than in cells cotransfected with miR-NC mimic (Figures 4B, 4C). Whereas, site-directed mutation of the seeded sequence in either site, completely abolished the effect of miR-342 on luciferase activity under the same conditions (Figures 4B, 4C). After that, RIP assays revealed that the enrichment of CCND1 mRNA was highly abundant by miR-342 overexpression in both A549 and H1299 cells, suggesting the endogenous interaction between miR-342 and CCND1 (Figures 4D, 4E). Next, we determined whether, if so, how miR-342 modulated CCND1 expression in NSCLC cells. In contrast to their counterparts, CCND1 expression was markedly reduced following miR-342 overexpression, while it was strikingly elevated by transfection of anti-miR342 (Figures 4F, 4G). Additionally, qRT-PCR data revealed that CCDN1 mRNA expression was prominently upregu- lated in NSCLC tissues compared with normal tissues (Supplementary Figure S1B). All these data strongly pointed to the role of CCND1 as a molecular target of miR-342 in NSCLC cells.

miR-342 overexpression-mediated anti-migration, antiinvasion, anti-cell cycle progression, and pro-apoptosis effects were abated by co-transfection of pcDNA-CCND1. To provide further mechanistic insight into the link between miR-342 and CCND1 on NSCLC cell progression, A549 and H1299 cells were co-transfected with miR-342 mimic and pcDNA-CCND1. In comparison to the negative control, the co-transfection of pcDNA-CCND1 significantly abrogated the inhibitory effect of miR-342 overexpression on cell migration and invasion abilities (Figures 5A-5D). Moreover, miR-342 mimic-mediated apoptosis promotion and cell cycle arrest were drastically reversed by co-transfection of pcDNACCND1 (Figures 5E-5J). These results together suggested that CCND1 mediated the regulatory effect of miR-342 on NSCLC cell progression in vitro.

Puerarin inhibited NSCLC cell progression in vitro by upregulating miR-342. Next, we further investigated whether the function of puerarin on NSCLC was associated 


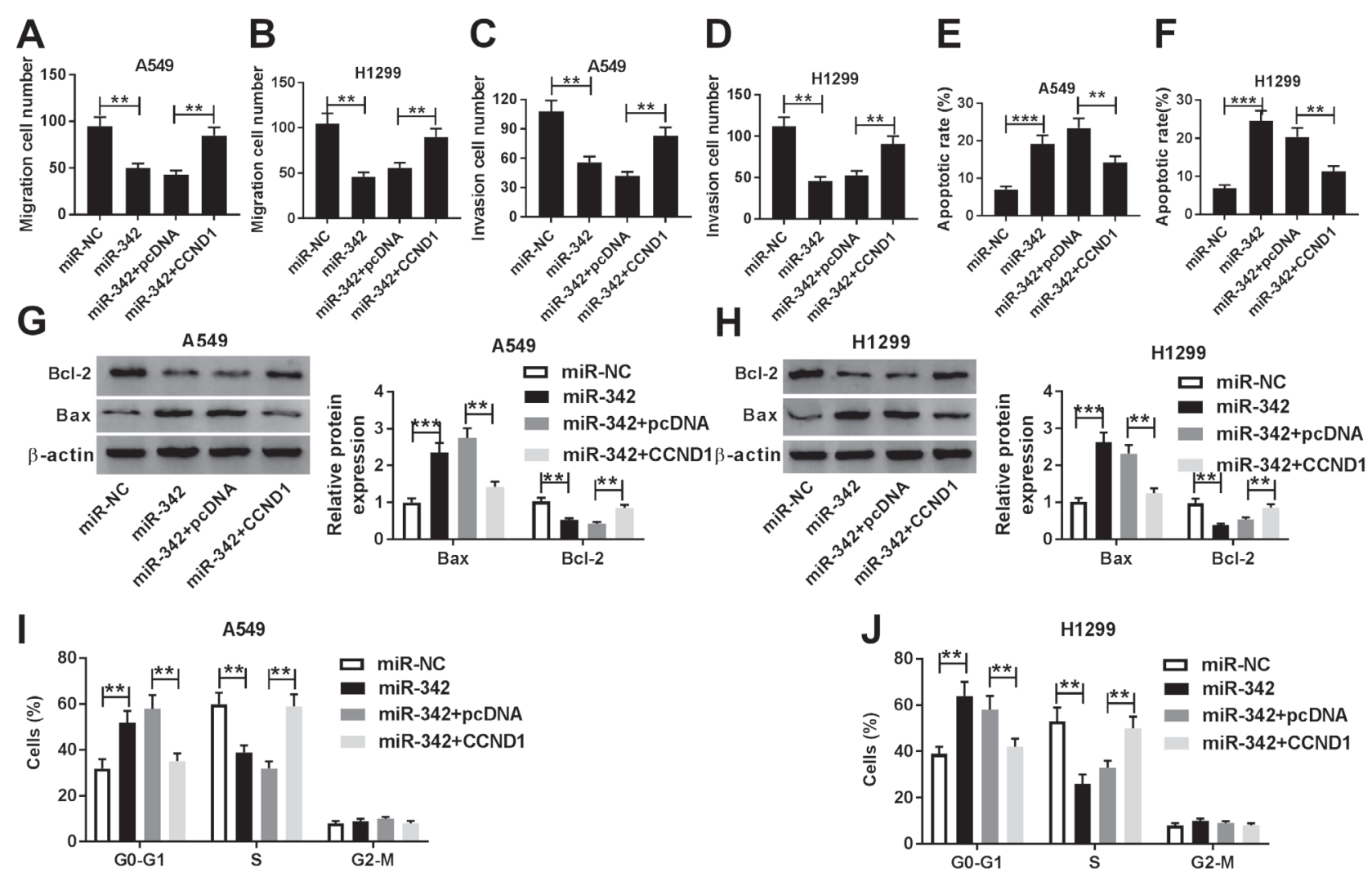

Figure 5. miR-342 exerted its regulatory effect on NSCLC cell progression by CCND1. A549 and H1299 cells were transfected with miR-NC mimic, miR-342 mimic, miR-342 mimic + pcDNA-NC or miR-342 mimic + pcDNA-CCND1, followed by the determination of cell migration (A and B) and invasion ( $C$ and $D)$ abilities, cell apoptosis by flow cytometry (E and F), the expression levels of Bax and Bcl-2 by western blotting ( $\mathrm{G}$ and $\mathrm{H}$ ), cell cycle progression by flow cytometry (I and $\mathrm{J}) .{ }^{\star *} \mathrm{p}<0.01$ or ${ }^{\star * *} \mathrm{p}<0.001$

with the miR-342/CCND1 axis. Herein, NSCLC cells were treated with different concentrations $(0,5,10$, and $20 \mu \mathrm{M})$ of puerarin for $48 \mathrm{~h}$, followed by the determination of miR-342 and CCND1 expression. As demonstrated by qRT-PCR, puerarin treatment resulted in increased miR-342 expression in a dose-dependent manner in both A549 and H1299 cells, eliciting a positive correlation between puerarin treatment and miR-342 expression (Figures 6A, 6B). Moreover, CCND1 expression was markedly reduced by puerarin treatment in both A549 and H1299 cells (Figures 6C, 6D). However, this effect was highly abolished by the transfection of anti-miR-342 (Figures 6C, 6D). These data together implied that puerarin hampered the expression of CCND1 by upregulating miR-342 in NSCLC cells. Subsequent experiment assays demonstrated that puerarin-mediated migration and invasion repression (Figures $6 \mathrm{E}-6 \mathrm{H}$ ), apoptosis enhancement (Figures 6I-6L), as well as cell cycle arrest (Figures 6M, $6 \mathrm{~N}$ ) were prominently abolished by the introduction of anti-miR-342. Together, these data strongly suggested that puerarin repressed NSCLC cell migration, invasion, and cell cycle progression and promoted the apoptosis by miR-342 in vitro.
Puerarin inhibited tumor growth in vivo via upregulating miR-342. Lastly, we determined the impact of puerarin in NSCLC progression in vivo using the xenograft mice model. These data revealed that compared to the negative control, puerarin treatment significantly repressed tumor growth, and this effect was strongly abrogated by the anti-miR-342 introduction (Figures 7A, 7B). Moreover, puerarin triggered a striking upregulation of miR-342 expression and a clear downregulation of CCND1 level in tumor tissues, and these effects were prominently reversed by anti-miR-342 administration (Figures 7C, 7D). These data together indicated that puerarin hindered tumor growth through miR-342 in vivo.

\section{Discussion}

Puerarin, a natural isoflavonoid from Pueraria lobata, has recently attracted increasing attention for its anticancer activity and induction of apoptosis in a wide variety of human cancers. For example, puerarin facilitated the apoptosis of bladder cancer cells by repressing of SIRT $1 / \mathrm{p} 53$ pathway [21]. Puerarin repressed colorectal cancer progres- 


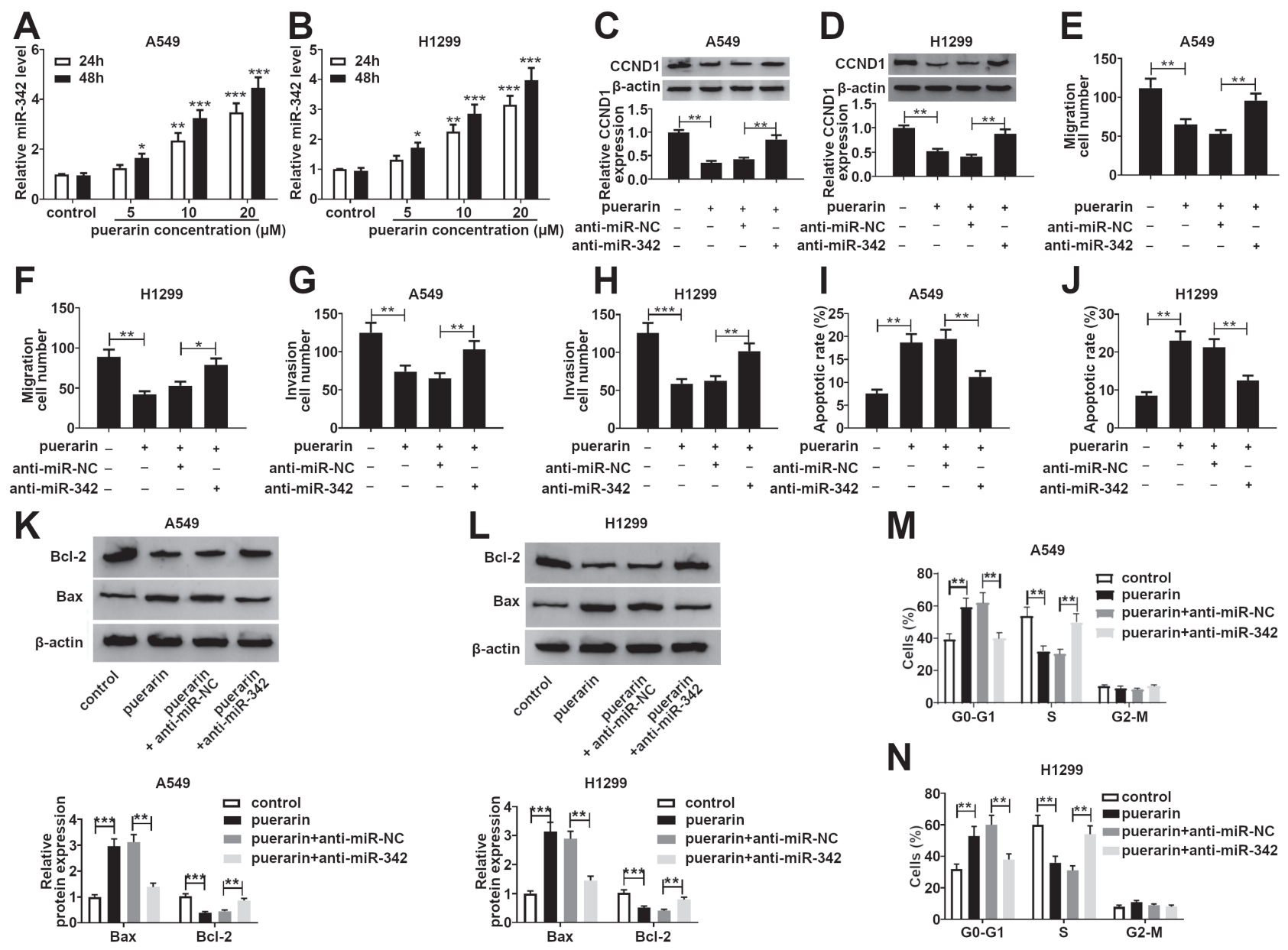

Figure 6. Puerarin inhibited CCND1 expression by upregulating miR-342. A549 (A) and H1299 (B) cells were treated with different concentrations $(0,5,10$, and $20 \mu \mathrm{M})$ of puerarin, followed by the determination of miR-342 expression by QRT-PCR. A549 and H1299 cells were transfected with or without anti-miR-NC or anti-miR-342 and then treated with or without $10 \mu \mathrm{M}$ of puerarin, followed by the measurement of CCND1 expression by western blotting $(\mathrm{C}$ and $\mathrm{D})$, cell migration $(\mathrm{E}$ and $\mathrm{F})$ and invasion $(\mathrm{G}$ and $\mathrm{H})$ by transwell assay, cell apoptosis by flow cytometry (I and $\mathrm{J})$, the levels of Bcl-2 and Bax by western blotting ( $\mathrm{K}$ and $\mathrm{L})$, cell cycle progression by flow cytometry $(\mathrm{M}$ and $\mathrm{N}) .{ }^{*} \mathrm{p}<0.05,{ }^{* *} \mathrm{p}<0.01$ or ${ }^{* * *} \mathrm{p}<0.001$

sion through the inhibition of cell growth and enhancement of cell apoptosis [22]. Moreover, puerarin was reported to weaken the expression of multidrug resistance 1 (MDR1) partially by nuclear factor kappa-B signaling pathway in adriamycin-resistant MCF-7 cells, possibly thereby reversing breast cancer drug resistance [23]. A previous document also demonstrated that puerarin triggered a distinct inhibition of M2 phenotype polarization, cell invasion, migration, as well as a reduction of angiogenesis factors expression in NSCLC macrophage [24]. In the present study, our data demonstrated that puerarin inhibited NSCLC cell viability and elevated cell apoptosis, in accordance with previous research [11]. Moreover, we validated that puerarin suppressed NSCLC cell migration, invasion, and cell cycle progression, consistent with the findings by Zeng et al. [25]. They also manifested that puerarin attenuated NSCLC pulmonary metastasis through suppressing the enzymatic activity of cyclooxygenase-2 in A549 cells. Notably, in the present research, our results showed that puerarin did not affect the viability of $16 \mathrm{HBE}$ cells, which possibly attributed to a lower concentration of puerarin treatment or certain addiction of NSCLC cells to puerarin. Emerging reports have demonstrated that the invasion of tumor cells is elevated through upregulating MMP9 and MMP2 expression [26, 27]. Our data also suggested that puerarin treatment resulted in decreased MMP9 and MMP2 levels in both A549 and H1299 cells, and this effect was abolished by the anti-miR-342 introduction (Supplementary Figures S2A, S2B), which partly provided evidence that invasion decrease was accompanied with the modulation of MMP9 and MMP2 expression in NSCLC cells. In the present work, when we determined the apoptosis of A549 and H1299 cells treated with puerarin for $24 \mathrm{~h}$, our data revealed that puerarin led to a feeble enhancement in cell apoptosis (Supplementary Figure 2C), and thus 
A

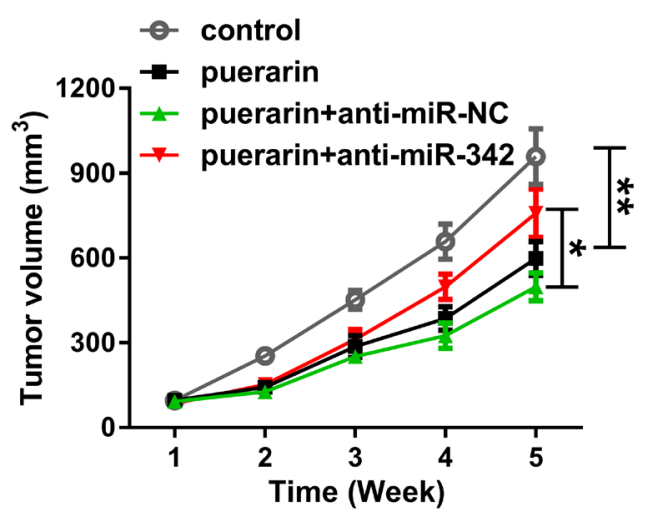

C

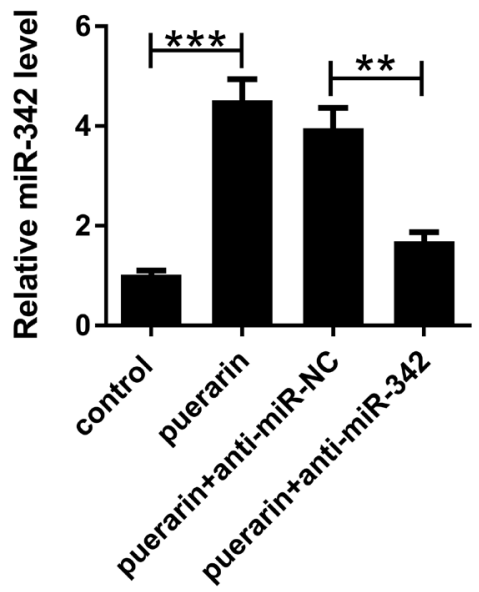

B

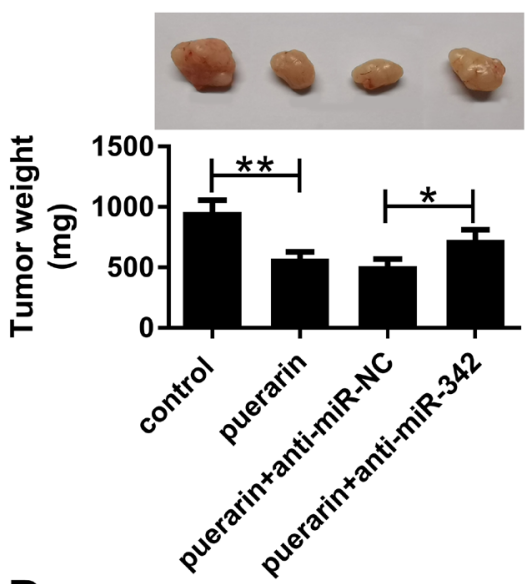

D

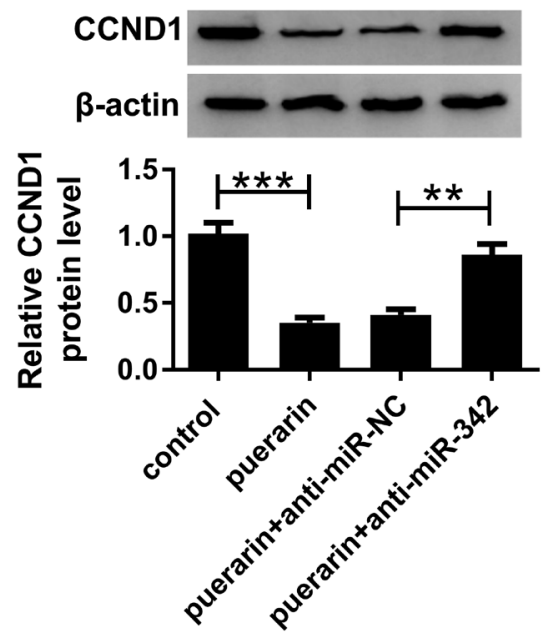

Figure 7. Puerarin inhibited tumor growth in vivo via upregulating miR-342. A549 cells $\left(1 \times 10^{7}\right)$ were subcutaneously injected into the nude mice. When the tumor grew to a mean volume of $100 \mathrm{~mm}^{3}$, simultaneous administration with puerarin (100 mg/kg/day) by oral gavage and intratumoral injection of anti-miR-342 or anti-miR-NC were carried out. At the end of the experiments, all mice were killed and tumors were excised. A) One week later, tumor volume was measured every other week. B) Representative images of the tumor were obtained and tumor weight was calculated. C, D) miR-342 and CCND1 levels were assessed by qRT-PCR and western blotting in the xenograft tissues. ${ }^{\star}$ p $<0.05,{ }^{* *}$ p $<0.01$ or ${ }^{\star * *}$ p $<0.001$

apoptosis promotion could feebly affect invasion reduction, but not significant.

miR-342 has been identified as a tumor-suppressive miRNA involved in the tumorigenesis and progression of multiple human cancers, such as gallbladder cancer [28], gastric cancer [29], and pancreatic cancer [30]. Additionally, a high level of miR-342 hampered cell proliferation, migration, and invasion of colorectal cancer cells possibly through the regulation of the expression of forkhead box M1 and Q1 [31]. Upregulated miR-342 was described to rescue metabolic disorder by directly targeting monocarboxylate transporter 1 in triple-negative breast cancer [32]. Besides, miR-342 was also reported to negatively modulate the transcriptional activity of MYC, an archetypical oncogene, via directly targeting E2F transcription factor 1 in human lung cancer [33]. In the present study, our results indicated that miR-342 overexpression hindered NSCLC cell migration, invasion, and cell cycle progression, and enhanced cell apoptosis, suggesting its tumor-suppressive property in NSCLC, consistent with earlier works $[17,18]$.

It is widely accepted that miRNAs function as important regulators in cellular physiopathology processes through posttranscriptional repression of target mRNAs. Therefore, microT-CDS software was used to search for the molecular targets of miR-342, and the predicted data showed two putative miR-342 binding sites in the 3'-UTR of CCND1 mRNA. CCND1 has been postulated to play a potential oncogenic role in human cancers, including bladder cancer [34], estrogen receptor positive breast cancer [35], and prostate cancer [36]. Moreover, accumulating evidence has 
suggested that CCND1 has oncogenic potential in the development and progression of NSCLC [37-39]. In the present study, we firstly confirmed that CCND1 was a direct target of miR-342. Moreover, miR-342 overexpression-mediated anti-migration, anti-invasion, anti-cell cycle progression, and pro-apoptosis effects were abated by cotransfection of pcDNA-CCND1. These data together established that miR-342 hampered NSCLC progression in vitro through targeting CCND1. Previous researches had found that some other miRNAs, such as let-7a and miR-3940-5p, could repress NSCLC progression via targeting CCND1 [40, 41].

Puerarin has been illuminated to play an anti-cancer activity via various mechanisms, including its regulatory function on the expression of some miRNAs, such as miR-16 and miR-133a-3p [19, 42]. Considering the suppressive effect of puerarin and miR-342 on NSCLC cell progression, we continued our study from the hypothesis that puerarin suppressed NSCLC progression by regulating miR-342 expression. To confirm this, A549 and H1299 cells were treated with puerarin, and our data firstly manifested that puerarin treatment led to increased miR-342 expression in a dose-dependent manner in NSCLC cells. More interestingly, we firstly demonstrated that puerarin inhibited CCND1 expression by upregulating miR-342 in NSCLC cells. Furthermore, our data substantiated that puerarin repressed NSCLC cell migration, invasion, and cell cycle progression and promoted apoptosis in vitro by miR-342. Additionally, we were first to highlight that puerarin hampered tumor growth in vivo by upregulating miR-342. Therefore, more researches about the regulatory relationship between puerarin and the miR-342/CCND1 axis will be performed in further work.

In conclusion, our study suggested that puerarin rescued NSCLC progression in vitro and in vivo at least partly through targeting the miR-342/CCND1 axis. The clinical significance of puerarin and its potential value as a therapeutic agent should be further investigated.

Supplementary information is available in the online version of the paper.

\section{References}

[1] BRAY F, FERLAY J, SOERJOMATARAM I, SIEGEL RL, TORRE LA et al. Global cancer statistics 2018: GLOBOCAN estimates of incidence and mortality worldwide for 36 cancers in 185 countries. CA Cancer J Clin 2018; 68: 394-424. https://doi.org/10.3322/caac.21492

[2] MOLINA JR, YANG P, CASSIVI SD, SCHILD SE, ADJEI AA. Non-small cell lung cancer: epidemiology, risk factors, treatment, and survivorship. Mayo Clin Proc 2008; 83: 584594. https://doi.org/10.4065/83.5.584

[3] ETTINGER DS, AISNER DL, WOOD DE, AKERLEY W, BAUMAN J et al. NCCN guidelines insights: non-small cell lung cancer, version 5.2018. J Natl Compr Canc Netw 2018; 16: 807-821. https://doi.org/10.6004/jnccn.2018.0062
[4] HERBST RS, MORGENSZTERN D, BOSHOFF C. The biology and management of non-small cell lung cancer. Nature 2018; 553: 446-454. https://doi.org/10.1038/nature25183

[5] ZHOU YX, ZHANG H, PENG C. Puerarin: a review of pharmacological effects. Phytother Res 2014; 28: 961-975. https://doi.org/10.1002/ptr.508

[6] CHEN G, ZHANG J, JIANNONG Y. Determination of puerarin, daidzein and rutin in Pueraria lobata (Wild.) Ohwi by capillary electrophoresis with electrochemical detection. J Chromatogr A 2001; 923: 255-262. https://doi.org/10.1016/ s0021-9673(01)00996-7

[7] CHENG M, LI X, GUO Z, CUI X, LI H et al. Puerarin accelerates re-endothelialization in a carotid arterial injury model: impact on vasodilator concentration and vascular cell functions. J Cardiovasc Pharmacol 2013; 62: 361-368. https://doi.org/10.1097/FJC.0b013e31829dd961

[8] ZHANG H, ZHANG L, ZHANG Q, YANG X, YU J et al. Puerarin: a novel antagonist to inward rectifier potassium channel (I K1). Mol Cell Biochem 2011; 352: 117-123. https://doi. org/10.1007/s11010-011-0746-0

[9] XIE W, DU L. Diabetes is an inflammatory disease: evidence from traditional Chinese medicines. Diabetes Obes Metab 2011; 13: 289-301. https://doi.org/10.1111/j.14631326.2010.01336.x

[10] SINGH AK, JIANG Y, GUPTA S, YOUNUS M, RAMZAN $\mathrm{M}$. Anti-inflammatory potency of nano-formulated puerarin and curcumin in rats subjected to the lipopolysaccharide-induced inflammation. J Med Food 2013; 16: 899-911. https:// doi.org/10.1089/jmf.2012.0049

[11] HU Y, LI X, LIN L, LIANG S, YAN J. Puerarin inhibits non-small cell lung cancer cell growth via the induction of apoptosis. Oncol Rep 2018; 39: 1731-1738. https://doi. org/10.3892/or.2018.6234

[12] CHEN T, CHEN H, WANG Y, ZHANG J. In vitro and in vivo antitumour activities of puerarin 6"-O-xyloside on human lung carcinoma A549 cell line via the induction of the mitochondria-mediated apoptosis pathway. Pharm Biol 2016; 54: 1793-1799. https://doi.org/10.3109/13880209.201 5.1127980

[13] IWAKAWA H-O, TOMARI Y. The functions of microRNAs: mRNA decay and translational repression. Trends Cell Biol 2015; 25: 651-665. https://doi.org/10.1016/j.tcb.2015.07.011

[14] LI Z, RANA TM. Therapeutic targeting of microRNAs: current status and future challenges. Nat Rev Drug Discov 2014; 13: 622-638. https://doi.org/10.1038/nrd4359

[15] HOU J, MENG F, CHAN LW, CHO W, WONG S. Circulating plasma microRNAs as diagnostic markers for NSCLC. Front Genet 2016; 7: 193. https://doi.org/10.3389/ fgene.2016.00193

[16] ZHOU Q, HUANG SX, ZHANG F, LI SJ, LIU C et al. Micro RNA s: A novel potential biomarker for diagnosis and therapy in patients with non-small cell lung cancer. Cell Prolif 2017; 50: e12394. https://doi.org/10.1111/cpr.12394

[17] XIE X, LIU H, WANG M, DING F, XIAO H et al. miR-342$3 p$ targets RAP2B to suppress proliferation and invasion of non-small cell lung cancer cells. Tumour Biol 2015; 36: 5031-5038. https://doi.org/10.1007/s13277-015-3154-3 
[18] XUE X, FEI X, HOU W, ZHANG Y, LIU L et al. miR-342$3 p$ suppresses cell proliferation and migration by targeting AGR2 in non-small cell lung cancer. Cancer Lett 2018; 412: 170-178. https://doi.org/10.1016/j.canlet.2017.10.024

[19] LIU X, LI S, LI Y, CHENG B, TAN B et al. Puerarin inhibits proliferation and induces apoptosis by upregulation of miR16 in bladder cancer cell line T24. Oncol Res 2018; 26: 1227 1234. https://doi.org/10.3727/096504018X15178736525106

[20] SHAN Z, CHENG N, HUANG R, ZHAO B, ZHOU Y. Puerarin promotes the proliferation and differentiation of MC3T3-E1 cells via microRNA-106b by targeting receptor activator of nuclear factor- $\mathrm{KB}$ ligand. Exp Ther Med 2018; 15: 55-60. https://doi.org/10.3892/etm.2017.5405

[21] YE G, KAN S, CHEN J, LU X. Puerarin in inducing apoptosis of bladder cancer cells through inhibiting SIRT1/p53 pathway. Oncol Lett 2019; 17: 195-200. https://doi.org/10.3892/ ol.2018.9600

[22] LI J, GUO C, LU X, TAN W. Anti-colorectal cancer biotargets and biological mechanisms of puerarin: Study of molecular networks. Eur J Pharmacol 2019; 858: 172483. https:// doi.org/10.1016/j.ejphar.2019.172483

[23] HIEN TT, KIM HG, HAN EH, KANG KW, JEONG HG. Molecular mechanism of suppression of MDR1 by puerarin from Pueraria lobata via NF- $\kappa B$ pathway and cAMPresponsive element transcriptional activity-dependent upregulation of AMP-activated protein kinase in breast cancer MCF-7/adr cells. Mol Nutr Food Res 2010; 54: 918-928. https://doi.org/10.1002/mnfr.200900146

[24] KANG H, ZHANG J, WANG B, LIU M, ZHAO J et al. Puerarin inhibits M2 polarization and metastasis of tumorassociated macrophages from NSCLC xenograft model via inactivating MEK/ERK 1/2 pathway. Int J Oncol 2017; 50: 545-554. https://doi.org/10.3892/ijo.2017.3841

[25] ZENG Y, SHEN ZJ, GU WZ, WU MH. Cyclooxygenase-2 mediates puerarin to inhibit the invasion and metastasis of lung cancer A549 cells. Transl Cancer Res 2017; 6: 493-501. https://doi.org/10.21037/tcr.2019.03.25

[26] WIERCINSKA E, NABER HPH, PARDALI E, VAN-DERPLUIJM G, VAN-DAM $\mathrm{H}$ et al. The TGF- $\beta /$ Smad pathway induces breast cancer cell invasion through the up-regulation of matrix metalloproteinase 2 and 9 in a spheroid invasion model system. Breast Cancer Res Treat 2011; 128: 657-666. https://doi.org/10.1007/s10549-010-1147-x

[27] GUTSCHALK CM, YANAMANDRA AK, LINDE N, MEIDES A, DEPNER $S$ et al. GM-CSF enhances tumor invasion by elevated MMP-2, -9 , and -26 expression. Cancer Med 2013; 2: 117-129. https://doi.org/10.1002/cam4.20

[28] WANG SH, MA F, TANG ZH, WU XC, CAI Q et al. Long non-coding RNA H19 regulates FOXM1 expression by competitively binding endogenous miR-342-3p in gallbladder cancer. J Exp Clin Cancer Res 2016; 35: 160. https://doi. org/10.1186/s13046-016-0436-6

[29] WANG F, LIANG S, LIU X, HAN L, WANG J et al. LINC00460 modulates KDM2A to promote cell proliferation and migration by targeting miR-342-3p in gastric cancer. Onco Targets Ther 2018; 11: 6383-6394. https://doi. org/10.2147/ott.s169307
[30] CHENG D, FAN J, MA Y, ZHOU Y, QIN K et al. LncRNA SNHG7 promotes pancreatic cancer proliferation through ID4 by sponging miR-342-3p. Cell Biosci 2019; 9: 28. https:// doi.org/10.1186/s13578-019-0290-2

[31] WENG W, OKUGAWA Y, TODEN S, TOIYAMA Y, KUSUNOKI M et al. FOXM1 and FOXQ1 are promising prognostic biomarkers and novel targets of tumor-suppressive miR-342 in human colorectal cancer. Clin Cancer Res 2016; 22: 4947-4957. https://doi.org/10.1158/1078-0432.CCR-160360

[32] ROMERO-CORDOBA SL, RODRIGUEZ-CUEVAS S, BAUTISTA-PINA V, MAFFUZ-AZIZ A, D'IPPOLITO E et al. Loss of function of miR-342-3p results in MCT1 over-expression and contributes to oncogenic metabolic reprogramming in triple negative breast cancer. Sci Rep 2018; 8: 12252. https://doi.org/10.1038/s41598-018-29708-9

[33] TAI MC, KAJINO T, NAKATOCHI M, ARIMA C, SHIMADA Y et al. miR-342-3p regulates MYC transcriptional activity via direct repression of E2F1 in human lung cancer. Carcinogenesis 2015; 36: 1464-1673. https://doi.org/10.1093/ carcin/bgv152

[34] SEILER R, THALMANN GN, ROTZER D, PERREN A, FLEISCHMANN A. CCND1/CyclinD1 status in metastasizing bladder cancer: a prognosticator and predictor of chemotherapeutic response. Mod Pathol 2014; 27: 87-95. https:// doi.org/10.1038/modpathol.2013.125

[35] ROY PG, PRATT N, PURDIE CA, BAKER L, ASHFIELD A et al. High CCND1 amplification identifies a group of poor prognosis women with estrogen receptor positive breast cancer. Int J Cancer 2010; 127: 355-360. https://doi.org/10.1002/ ijc. 25034

[36] NAKAMURA Y, FELIZOLA SJ, KUROTAKI Y, FUJISHIMA F, MCNAMARA KM et al. Cyclin D1 (CCND1) expression is involved in estrogen receptor beta $(\mathrm{ER} \beta)$ in human prostate cancer. Prostate 2013; 73: 590-595. https://doi. org/10.1002/pros.22599

[37] YOU W, CHEN B, LIU X, XUE S, QIN H et al. Farnesoid $\mathrm{X}$ receptor, a novel proto-oncogene in non-small cell lung cancer, promotes tumor growth via directly transactivating CCND1. Sci Rep 2017; 7: 591. https://doi.org/10.1038/ s41598-017-00698-4

[38] ZHAO M, XU P, LIU Z, ZHEN Y, CHEN Y et al. Dual roles of miR-374a by modulated c-Jun respectively targets CCND1-inducing PI3K/AKT signal and PTEN-suppressing Wnt/beta-catenin signaling in non-small-cell lung cancer. Cell Death Dis 2018; 9: 78. https://doi.org/10.1038/s41419017-0103-7

[39] ZHAO L, LIU L, DONG Z, XIONG J. miR-149 suppresses human non-small cell lung cancer growth and metastasis by inhibiting the FOXM1/cyclin D1/MMP2 axis. Oncol Rep 2017; 38: 3522-3530. https://doi.org/10.3892/ or.2017.6047

[40] ZHAO W, HU JX, HAO RM, ZHANG Q, GUO JQ et al. Induction of microRNA-let-7a inhibits lung adenocarcinoma cell growth by regulating cyclin D1. Oncol Rep 2018; 40: 1843-1854. https://doi.org/10.3892/or.2018.6593 
[41] REN K, LI Y, LU H, LI Z, HAN X. miR-3940-5p functions as a tumor suppressor in non-small cell lung cancer cells by targeting cyclin D1 and ubiquitin specific peptidase- 28 . Transl Oncol 2017; 10: 80-89. https://doi.org/10.1016/j.tranon.2016.11.004
[42] LI Z, XU W, REN X, XU J, CHEN J. Puerarin promotes DUSP1 expression by regulating miR-133a-3p in breast cancer. Mol Med Rep 2019; 19: 205-212. https://doi.org/10.3892/ mmr.2018.9682 


\section{Puerarin alleviates the progression of non-small cell lung cancer by regulating the miR-342/CCND1 axis}

S. R. HUANG ${ }^{1, *}$, S. S. JIN ${ }^{2, *}$, B. XU⿱⺌${ }^{3}$, R. P. WANG ${ }^{4, *}$

Supplementary Information
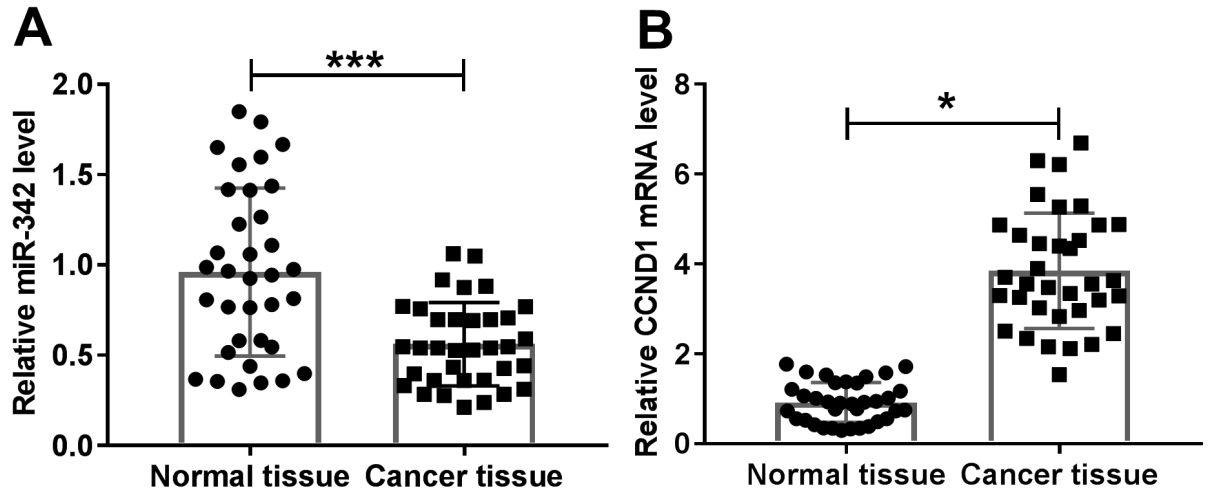

Supplementary Figure S1. miR-342 was downregulated and CCND1 was upregulated in NSCLC tissues. (A and B) miR-342 and CCND1 mRNA levels were assessed by qRT-PCR in 35 pairs of NSCLC tissues and matched noncancerous tissues. ${ }^{\star} p<0.05$ or ${ }^{\star * \star} p<0.001$.
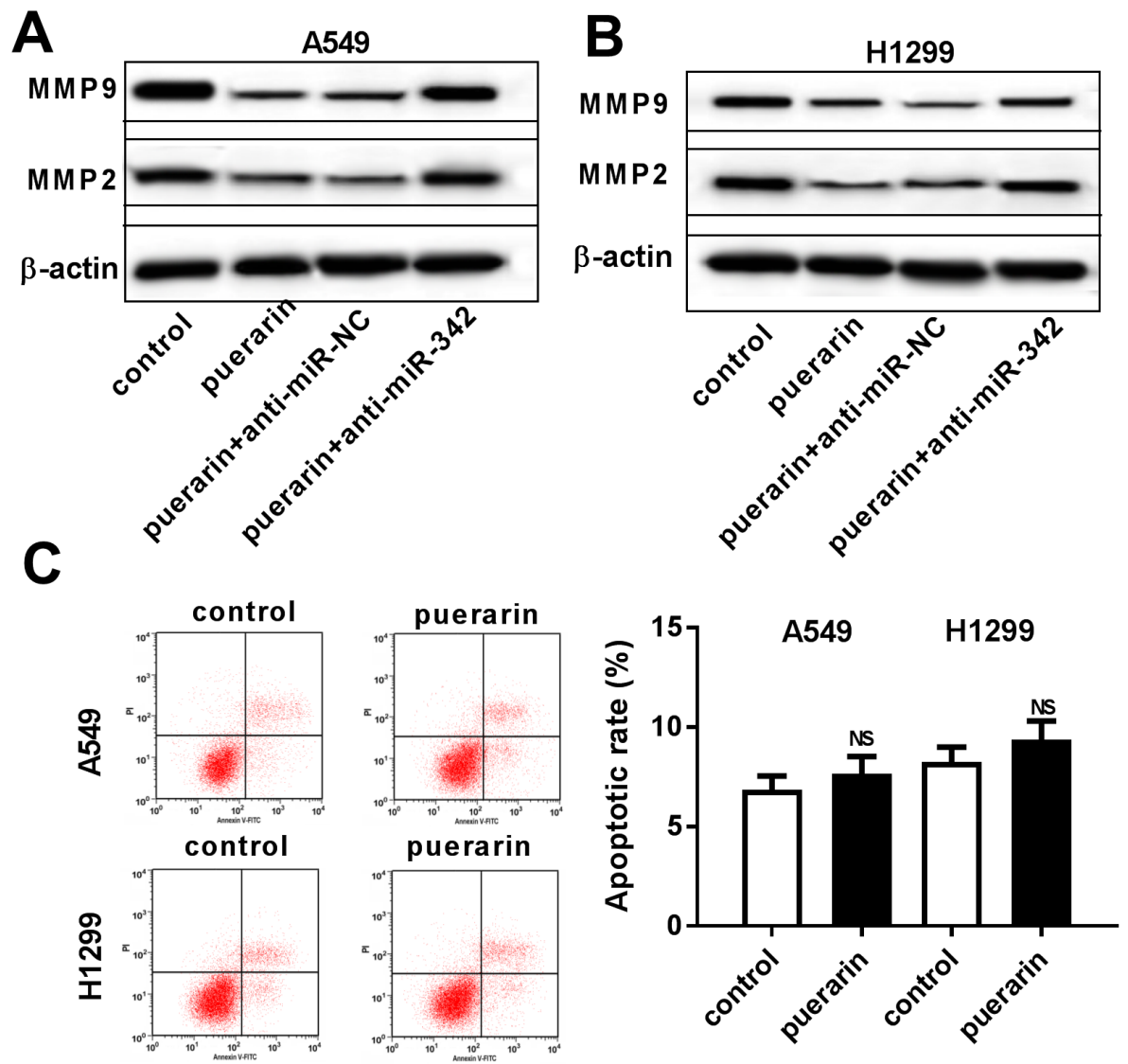

Supplementary Figure S2. The effect of puerarin on the expression of MMP9 and MMP2 and cell apoptosis. (A and B) A549 and H1299 cells were transfected with anti-miR-NC or anti-miR-342 before puerarin for $48 \mathrm{~h}$, followed by the detection of MMP9 and MMP2 levels. (C) A549 and H1299 cells were treated with puerarin for $24 \mathrm{~h}$, and then cell apoptosis was determined. $\mathrm{NS}=$ no significant 